Research

\title{
Agricultural chemical exposures and birth defects in the Eastern Cape Province, South Africa A case - control study Gudrun A Heeren*1,3, Joanne Tyler ${ }^{2}$ and Andrew Mandeya ${ }^{2}$
}

Address: ${ }^{1}$ Department of Public Health, Cecilia Makiwane Hospital, Mdantsane, P.O. Box 691, East London 5200, South Africa, ${ }^{2}$ Department of Science and Statistics, University of Fort Hare, Private Bag X1413, Alice 5700, South Africa and Present address - University of Pennsylvania Annenberg School of Communication Center of Health Behavior, 3535 Market Street Suite520 Philadelphia PA 19104-3309 USA

Email: Gudrun A Heeren* - aheeren@asc.upenn.edu; Joanne Tyler - JTyler@ufh.ac.za; Andrew Mandeya - AMandeya@ufh.ac.za

* Corresponding author

Published: 04 October 2003

Environmental Health: A Global Access Science Source 2003, 2:II

This article is available from: http://www.ehjournal.net/content/2/I/I I

(C) 2003 Heeren et al; licensee BioMed Central Ltd. This is an Open Access article: verbatim copying and redistribution of this article are permitted in all media for any purpose, provided this notice is preserved along with the article's original URL.
Received: 22 November 2002

Accepted: 04 October 2003

\begin{abstract}
Background: South Africa is one of the major users of pesticides on the African continent. The Eastern Cape is the second largest province in South Africa. There has been growing concern about the occurrence of certain birth defects which seemed to have increased in the past few years. In this paper we investigate associations between exposure to agricultural chemicals and certain birth defects. Few such studies have been undertaken in the developing world previously.
\end{abstract}

Methods: Between September 2000 and March $200 \mathrm{I}$ a case - control study was conducted among rural women in the area of the Eastern cape to investigate the association between women's exposure to pesticides and the occurrence of birth defects. Information on birth defects was obtained from the register of the Paediatrics Department at the Cecilia Makiwane Hospital in Mdantsane, one of the largest referral hospitals in the province. The cases were children who were diagnosed with selected birth defects. The controls were children born in the same areas as the cases. Exposure information on the mothers was obtained by interview concerning from their activities in gardens and fields. Data were analysed using conditional logistic regression.

Results: A total of 89 case mothers and 178 control mothers was interviewed. Babies with birth defects were seven times more likely to be born to women exposed to chemicals used in gardens and fields compared to no reported exposure (Odds Ratio 7.18, 95\% Cl 3.99, 13.25); and were almost twice as likely to be born to women who were involved in dipping livestock used to prevent ticks (OR I.92, 95\% Cl I.I5, 3.14). They were also 6.5 times more likely to be born to women who were using plastic containers for fetching water $(\mathrm{OR} 6.5,95 \% \mathrm{Cl} 2.2,27.9)$. Some of these containers had previously contained pesticides (OR I.87, $95 \% \mathrm{CI}$ I.06, 3.3I).

Conclusions: These findings suggest a link between exposure to pesticides and certain birth defects among the children of rural South African women who work on the land. Education programmes for women alerting them to the dangers to their babies from the use of pesticides and alternative farming methods and elimination of the reuse of pesticide containers are indicated as preventive measures. 


\section{Background}

South Africa is one of the major users of pesticides on the African continent. However, detailed information on the types of pesticides used is not available. About a fifth of South Africa's arable land is used for agriculture, with approximately a tenth of the economically active population being employed in the agricultural sector. Agriculture is one of the most important income generating activities and the fifth biggest employer in the country [1].

The Eastern Cape is the second largest province in South Africa, covering an area of 169580 square kilometres. Commercial farming is characterised by use of agricultural machinery and consequent decreased manpower requirements. With technology, pest and weed control with chemical spraying techniques has been used extensively. The majority of the commercial farm workers are men. By contrast, women dominate the subsistence farming and vegetable gardening sector. Most sprayers on commercial farms have some informal education in the use of pesticides, but the predominantly female subsistence farmers are often poorly educated, with little or no awareness about the safe use of pesticides.

There is growing concern that the occurrence of certain birth defects has been increasing in the Eastern Cape province. From January to March 2000, a pilot study was conducted in a rural farming area of the Eastern Cape to examine whether there was an association between pesticide exposure and adverse health effects (Heeren GA: Pesticide exposure and adverse health impact in the Eastern Cape. A Pilot study around East London. Presented at the National Environmental Health Conference Durban August 2000. Unpublished paper). The results of the study suggested that there are adverse health problems as a result of exposure to pesticides. This paper reports the results of a more detailed subsequent study on the association of birth defects to agricultural exposure. During the time September 2000 till March 2001, a case-control study interviewing the mothers of 89 cases and 178 controls (Ratio 1:2) was conducted in the area

\section{Methods \\ Setting}

South Africa shares borders with Namibia, Botswana, Zimbabwe, Swaziland, Mozambique and is surrounded on two sides by the Atlantic and the Indian Oceans. The country is divided into nine provinces, of which the Eastern Cape, is at the southern tip of South Africa alongside the Indian Ocean. Since the 1994 election, the former "homeland" governments of Transkei, Ciskei, and parts of Bophutatswana have been incorporated into the Eastern Cape. It is not only the second largest province, but also one of the poorest. The languages spoken in the Eastern Cape area include Sotho, Afrikaans, Xhosa and English, but the language spoken in the study area was Xhosa. The study area is very rural and all women interviewed were black.

There are few places of paid employment such as shops, schools and clinics. The women stay "at home" and attempt to generate income from their food gardens and fields. The average monthly income in the study population was R500-R1000 (exchange rate at time of study, Rand : US dollar 8.7 : 1), while a teacher earns R 4000. Many women depend on gardening and fieldwork to contribute towards the income of the family. More than $82 \%$ of the women fetch water from outside their homes-, from a communal tap, river or dam. About $40 \%$ use wood (which they have to collect) as their fuel for daily cooking.

\section{Selecting the Study Areas}

Data from the records at Cecilia Makiwane Hospital, a large referral hospital, for the years 1998, 1999 and 2000 were reviewed with regard to selected birth defects treated in the hospital. There appeared to be an increase in the annual number of birth defects treated at the hospital during these years, and after mapping, the areas with the highest numbers of cases were chosen for the study.

\section{Definition of cases}

Cases were chosen from the Hospital register of the Department of Paediatrics on the basis of ICD 9 codes for birth defects (Table 1). These categories of defects are suspected to be associated with exposure to some pesticides [2]. For the initial analyses of the data, all birth defects mentioned in Table 1 were considered. However, not all mothers of these cases could be interviewed due to the distance and difficulties of reaching the mothers of the cases in the area.

Table I: ICD 9 Birth defects

\begin{tabular}{ll}
\hline ICD - Code & Disease \\
\hline $740.0-742.9$ & Nervous system defects \\
$745.0-747.9$ & Cardiovascular defects \\
$749.0-749.2$ & Oral defect \\
752.6 & Epispadia or hypospadias \\
$754.0-754.9$ & Clubfoot \\
756.9 & Musculoskeletal defects \\
$759.7-759.9$ & Unspecified defects \\
\hline
\end{tabular}

\section{Definition of controls}

The controls were defined as children who were healthy and without visible malformations, born within the same birth year as a matched case (plus minus 1 year) and in the same area as the cases. For each case, two controls were chosen. These controls were identified by clinic nurses 
who assisted with the interviews. The controls were from the same area as the cases and were similar in socio-economic background and environment like access to water, gardening, animals and other living conditions.

\section{Exposure assessment}

A questionnaire was designed and used as the principal method of data collection for the study. The questionnaire was pre-tested by the data collectors and within the community. At each clinic, one nurse was briefed about the purpose of the study and trained to administer the questionnaire. The nurses obtained oral consent from each mother interviewed before administering the questionnaire. Data collectors were trained in the interpretation of the questions and completion of the questionnaire. A field guide was also developed and used to ensure consistency and content validity.

Socio-economic and demographic variables were obtained for each woman. These included geographical region, age, education, marital status, number of live births, income and employment. The women were also classified according to their use of agricultural chemicals, whether they kept domestic animals and the type of container they used for fetching and storage of water for household use. Birth defect status was used as the dependent variable.

To assess exposure to pesticides, questions about activities in and around the house were included in the questionnaire. Most mothers interviewed said they were unemployed, however they contributed to the family income by working in their own garden and fields, where some of the women were exposed to pesticides. The South African winter season is generally not as severe as it is in the Northern Hemisphere, and agricultural harvests are possible throughout the year. The livestock, such as cattle, goats and/or sheep, are regularly dipped as a tick-control measure, using dips containing flumechin. Dipped animals were therefore considered another source of exposure to pesticides. A further source of exposure in the study population was the reuse of plastic containers that had previously been used for the storage of agricultural chemicals. These containers were subsequently used for fetching and storing water.

In the questionnaire, the women were also asked whether they smoked cigarettes or consumed alcohol, but only one mother reported smoking and none of the mothers reported drinking alcohol. These explanatory variables were thus not considered in the analyses.

Both the cases and the controls were asked the same questions, and neither the case nor the control mothers were informed about the study hypothesis. The interviewers were nurses, who were working in the Clinics and known in the community in this very rural area where the study was conducted. These trained interviewers were not blind to the case status of subjects interviewed.

\section{Statistical Analysis}

The statistical analysis was undertaken using Epi-Info 6.4 and SAS 6.10 statistical software packages. The analysis was carried out according to the type of exposure. Exposure to agricultural chemicals, dipping of animals, and the use of re-used plastic containers, are the three types of exposure considered in this study. Chemical exposure was compared to non-chemical exposure, and animal exposure was compared to non-animal exposure. Water containers were classified as tap water (no container necessary), plastic containers and metal containers.

With birth defect as the response variable, conditional logistic regression of birth defect according to the different type of exposure, was used as the principal method of analysis. All statistical significance tests were performed at the $5 \%$ level of significance. Matching was undertaken with respect to age, occupation, ownership of live stock (cows/goats/sheep) and location.

\section{Ethics Committee}

The Ethics Committee of Fort Hare University approved this study. The study was also approved by the Ethics Committee of the Department of Health (Region C) in the Eastern Cape and by each Clinic committee in the region.

\section{Results \\ Socio-economic background \\ Age groups}

Ages of mothers in this study ranged from 14 to 51 years, with mothers in the control group 14 to 48 years, whilst for the cases they ranged between 18 and 51 years (Table 2 ). About $7 \%$ percent of the women did not know their date of birth. Therefore, the numbers do not add up to the total numbers in the study. Of all the women interviewed, $62 \%$ were single mothers and had no knowledge of the whereabouts of their child's father.

\section{Education and Income}

Generally, the mothers of cases were less well-educated than those of the control group (Table 3). Information on income was considered unreliable since most of the mothers were technically unemployed (Table 4). However, many of the mothers sell products informally at the market and earn an inconsistent income from this (Table $5)$.

\section{Water source, transportation and storage}

Only $18 \%$ of the mothers have access to tap water inside the house. The majority of women obtain water outside 
Table 2: Age group distribution in Cases and Control mothers

\begin{tabular}{lllll}
\hline Age groups & Cases & \multicolumn{3}{l}{ Controls } \\
\hline & $\mathrm{Nr}$ & $\%$ & $\mathrm{Nr}$ & $\%$ \\
\hline $14-19$ & 9 & 10.1 & 15 & 8.4 \\
$20-24$ & 16 & 17.9 & 46 & 25.8 \\
$25-29$ & 17 & 19.1 & 42 & 23.5 \\
$30-34$ & 22 & 24.8 & 34 & 19.6 \\
$35-39$ & 6 & 6.7 & 27 & 15.1 \\
$40-44$ & 7 & 7.8 & 9 & 5.1 \\
$45+$ & 2 & 2.2 & 4 & 2.3 \\
No date of birth & 10 & 11.2 & 1 & 0.5 \\
\hline
\end{tabular}

Table 3: Education of the mothers of the Cases and Controls

\begin{tabular}{lllll}
\hline Education & Cases & \multicolumn{3}{l}{ Controls } \\
\hline & $\mathrm{Nr}$ & $\%$ & $\mathrm{Nr}$ & $\%$ \\
\hline No schooling & 7 & 7.9 & 8 & 4.5 \\
STD I - 3 & 11 & 12.4 & 20 & 11.2 \\
STD 4 - 6 & 23 & 25.8 & 20 & 11.2 \\
STD 7 - 8 & 16 & 18.0 & 54 & 30.1 \\
STD 9 up to Matric & 21 & 23.6 & 63 & 35.4 \\
Tertiary & 6 & 6.7 & 10 & 5.6 \\
\hline
\end{tabular}

Table 4: Employment status of the mothers of the cases and controls

\begin{tabular}{lllll}
\hline Employment status & $\begin{array}{l}\text { Cases } \\
\mathrm{Nr}\end{array}$ & $\%$ & $\begin{array}{l}\text { Controls } \\
\mathrm{Nr}\end{array}$ & $\%$ \\
\hline Formal & $\mathrm{II}$ & 12.4 & 32 & 18.0 \\
Informal/Self-empl & $1 \mathrm{I}$ & 12.3 & 19 & 10.6 \\
Pension & 10 & 11.2 & 14 & 7.9 \\
Unemployed & 54 & 60.7 & $10 \mathrm{I}$ & 56.7 \\
Other & 3 & 3.4 & 12 & 6.7 \\
\hline
\end{tabular}

Table 5: Income of the mothers of cases and control

\begin{tabular}{lllll}
\hline Income & $\begin{array}{l}\text { Cases } \\
\mathrm{Nr}\end{array}$ & $\%$ & $\mathrm{Nr}$ & Controls \\
& & & & \\
\hline R 500 & 78 & 87.6 & 142 & 79.8 \\
R 1000 & 5 & 5.6 & 19 & 10.7 \\
R 2000 & 2 & 2.2 & 13 & 7.3 \\
R 3000+ & 4 & 4.5 & 4 & 2.2 \\
\hline
\end{tabular}

their homes, from communal taps, rivers, dams or rain tanks. The women who have to fetch water from outside the house use different types of containers. Metal containers were used by $12 \%$, while plastic containers were used by $72 \%$ of all women. In $7.5 \%$ of the cases, these plastic containers were reused containers which had previously contained agricultural chemicals or other kinds of chemical liquids.

\section{Agricultural chemical exposure analysis}

Conditional logistic regression was performed with birth defect as the response variable, while exposure to agricultural chemicals, keeping of domestic animals, type of water container, the socio-economic and demographic variables were used as explanatory variables. The analyses showed that the risk of birth defects was not significantly associated with any of the demographic variables. Exposure to agricultural chemicals, to dipping domestic animals, and use of type of water container had statistically significant associations with birth defects. These three variables were then analysed separately giving the results reported below.

\section{Domestic animals}

Of the 267 women in the study population, $172 \mathrm{kept}$ domestic animals. Nearly $60 \%$ of the cases kept animals while $68 \%$ did so among the controls. Only domestic animals like cattle, goats and sheep are dipped. Other household animals are not normally dipped and therefore do not appear in the analyses. Thus, only cattle, goats and sheep were considered in further analyses. Information obtained about the chemical contents of the dip used showed that it contained flumechin, a pesticide used to kill ticks and tsetse flies. The risk of birth defect associated with overall exposure to these domestic animals was found to be statistically significant with an odds ratio of $1.92,(95 \% \mathrm{CI}, 1.15,3.14), \mathrm{p}=0.01$. Only $36.3 \%$ of these animals were regularly dipped. About $48.3 \%$ of the cases dipped animals, compared with $30.3 \%$ of the controls.

Exposure to cattle was found to be significantly associated with risk of birth defects, while exposure to goats and sheep was not significant at the $5 \%$ level. The results of the analysis of dipping of animals and birth defects are shown in Table 6.

Table 6: Risk of birth defects in relation to animal exposure.

\begin{tabular}{llll}
\hline Animals & Odds Ratio & $95 \% \mathrm{Cl}$ of OR & P-value \\
\hline Cattle & 2.53 & $1.40-4.70$ & 0.0014 \\
Goats & 1.18 & $0.78-3.95$ & 0.7650 \\
Sheep & 0.74 & $0.10-4.11$ & 0.7180 \\
\hline
\end{tabular}


Table 7: Odds ratios tap water versus water container and reuse of plastic container

\begin{tabular}{lll}
\hline Container & Odds Ratio & $95 \% \mathrm{Cl}$ of OR \\
\hline Tap vs. Plastic & 6.53 & $2.2-27.9$ \\
Used plastic vs. new plastic * & 1.87 & $1.06-3.31$ \\
Tap vs. Metal & 2.76 & $0.76-13.18$ \\
\hline
\end{tabular}

* Used plastic container had previously been used to store chemicals, whereas new container not. Tap stands here for the tap in the house, not the communal tap.

\section{Water containers}

In the study area only $18 \%$ of households had access to tap water in the house, all other households having to fetch water from an outside source, such as a communal tap, a dam or a river. Therefore three types of container used for the storage of household water were identified in this study, namely, tap water (use of tap water within the house, meaning no container necessary), plastic container and metal container. As shown in Table 7 the analyses showed that women who use metal containers compared with those who used tap water had an increased risk of having a baby with birth defects which was not statistically significant. However, the use of plastic container as compared with tap water or metal container was significantly associated with birth defects. Women who used plastic container were more than six times as likely to have a baby with a birth defect than were those who used tap water. In a more detailed analysis of the plastic container, the containers were divided into two categories: reused and non-reused (new) container. The reused container had previously been used to store chemicals whereas the non-reused (new) container had never been used to store chemicals. It was found that the odds of having babies born with birth defects were 1.87 times higher with reused container compared with non - reused (new) container.

\section{Agricultural chemicals}

Most of the mothers were involved in vegetable gardening and subsistence farming, although on a small scale. Of the cases, $80 \%$, and $74 \%$ of controls were actively involved in food gardening and farming. The use of agricultural chemicals (pesticides), was reported by $60 \%$ of the cases and $12.4 \%$ of the controls. The most commonly used agricultural chemicals and soil additives were insecticides, organophosphates and "Blue death", the latter a mixture of three different chemicals: carbaryl, carbufuran and campechlor (toxaphene;campechlor has been banned in South Africa since 1970, but clearly is still in use, Department of Agriculture 1999). The proportion of mothers using these pesticides is shown in Fig 1.
Table 8: Odds ratios for exposure to agricultural chemicals compared non - exposure

\begin{tabular}{lll}
\hline Chemical & Odds Ratio & $95 \% \mathrm{Cl}$ \\
\hline Chemicals (any) & 7.18 & $3.99-13.25$ \\
Organophosphate & 7.84 & $5.78-12.63$ \\
Pesticide & 6.00 & $2.75-13.49$ \\
Blue death & 9.11 & $4.95-17.88$ \\
Insecticide & 4.11 & $0.48-35.10$ \\
Fertilizer & 1.03 & $0.05-7.19$ \\
\hline
\end{tabular}

Blue death", is a mixture of three different chemicals, carbaryl, carbufuran and camphechlor (although campechlor has been banned in South Africa since 1970. Department of Agriculture 1999.)

As shown in Table 8, the use of agricultural chemicals had a significant association with the occurrence of birth defects. Women exposed to any agricultural chemical were more than seven times as likely to have babies born with a birth defect than were those not exposed to any chemicals. These chemicals were further analysed and it was found that, women who used insecticides were at increased risk, but the increase was not statistically significant. Use of fertilizers carried no increased risk. The women exposed to chemicals such as pesticides, "blue death", and organophosphate were more than six times as likely to have babies born with birth defects as were those exposed to no chemicals.

\section{Discussion}

Most studies concerning the use of pesticides focus on people who have been occupationally exposed to pesticides. Occupational exposure is easier to determine because the type of exposure and the duration of exposure are more likely to be accurately known. Moreover, studies on occupational exposures tend to consider male rather than female exposure [3]. Studies on exposure to pesticides among females and the adverse effects on reproductive health are less frequent, but include a few studies in the late 1960s and some during the 1990s [47] (Garcia AM: Epidemiological evidence of pesticide exposure and adverse reproductive and developmental effects in humans. Unpublished papers. 1998, Department of Preventive Medicine and Public Health. Faculty of Social. Sciences University of Valencia Avda. Tarongers s/ n. 46022 Valencia Spain.) Studies have suggested a possible influence of exposure to pesticides on the risk of adverse reproductive outcomes. These studies covered maternal, paternal or both parents' occupational pesticide exposure, and examined congenital malformation [5-7], miscarriages [8] and stillborn babies with congenital malformation $[9,10]$. 


\section{Gardenchemicals}

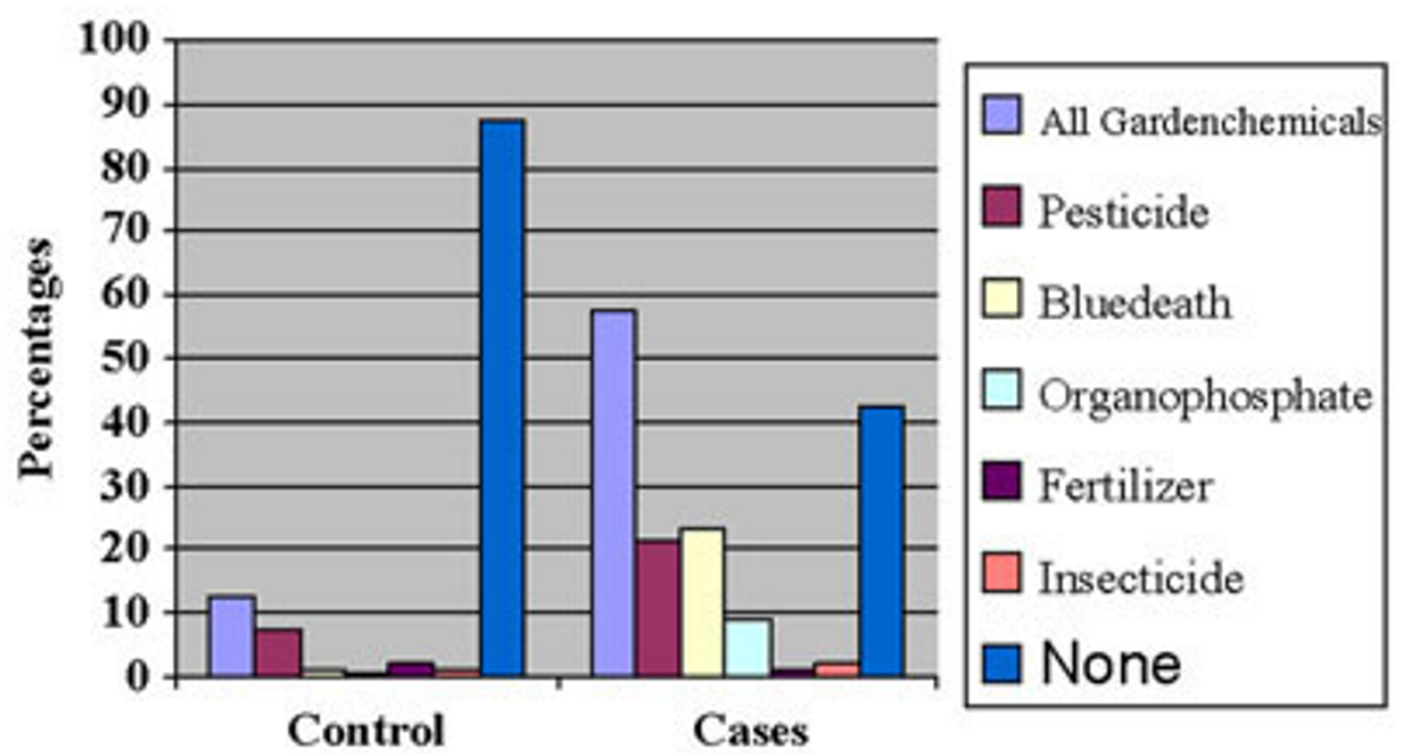

Figure I

Distribution of pesticide use by type of agricultural chemical.

Most studies of exposure to pesticides have been conducted in the developed world. Only a few studies have been undertaken in the developing world [11], including some studies undertaken in South Africa, in the Western Cape $[3,4,12,13]$. However, all of these studies have focused on occupational exposure and mainly on male workers. A study in Columbia [14], which focused on couples and included both male and female workers and their reproductive health, is one of the very few such studies carried out in a developing country. Studies on agricultural chemical exposure and adverse reproductive outcomes have mainly been undertaken in the developed world. [15-20].

Studies in developed countries usually have much more auspicious study circumstances, such as enrolling married couples, a high level of knowledge of the kind of pesticides used, information about the duration of the exposure, or the use of a prospective research design. Further, there are frequently data available regarding the father's activity and whether the father, the mother or both had been exposed to some kind of chemical and when the time of the possible exposure occurred. Sometimes there is exact information about gestation time and time of con- ception and possible early losses of pregnancies were recognized.

In comparison, in the rural environment of the developing world the research conditions are very different. In this study an attempt has been made to establish an association between chemical exposure and birth defect outcome, without the availability of any of the abovementioned advantages. Nearly $62 \%$ of the mothers were single and more than 58\% were unemployed. The exposure assessment had to be taken from the women's activities, such as food gardening, fieldwork and dipping of livestock. Prior to this study, a pilot-study focusing on pesticide exposure and adverse health impact in the Eastern Cape showed differences in the behavioural pattern of those people occupationally exposed to pesticides and those who used pesticides privately (Heeren GA: Pesticide exposure and adverse health impact in the Eastern Cape. A Pilot study around East London. Presented at the National Environmental Health Conference in Durban August 2000, Unpublished paper).

In the current study chemical exposure has been linked to a negative reproductive outcome. The results of this study 
thus confirm the findings of similar studies carried out in the developed world $[5-8,16,18,20]$.

There remains a need for further studies which are broader and larger in terms of the number of women in the study and more variables to better control potential confounding. Such variables could be used in a combination of analyses of ground water and of food in order to confirm residues in food. Because the prevention of certain birth defects is possible, everything should be done to reach this goal.

\section{Conclusions}

The results of the study show that there is a statistically significant association between birth defects and the exposure of the mothers to certain types of agricultural chemicals. There were three types of exposure found to be significantly associated with birth defects. One kind of exposure was the use of plastic containers previously used for the storage of agricultural chemicals but later used for storing of water for household use. The second kind was the use of particular garden chemicals. The third kind of exposure was found to be keeping of cattle which needed to be dipped. No socio-economic or demographic variables included in the analysis were significantly associated with birth defects.

Workers are included in many education programmes on the use of pesticides, but the women who care for the food of their families are in most cases not educated in any way [21]. There is an urgent need for an awareness campaign with regard to the use of pesticides among the many women who are not aware of the danger of using chemicals. Education efforts to introduce alternative farming methods should be encouraged, as this will reduce reliance on chemical products which are not necessary for successful cultivation [22]. The same applies in respect of the reused plastic containers for fetching water.

Access to water is a major problem in all rural areas in Africa. If water needs to be fetched from a communal tap, rain tank, river or dam, a container is needed. Poor women use any container available. A possible way of reducing the problem is to charge a deposit on the chemical containers, refundable on return. Another suggestion might be that households in rural areas should be supplied with a water container, which is safe to use for fetching and storing water.

A national birth register should be established to record information on the child's date of birth, gestational age, birthweight and, in case of a defect, the ICD code. In addition, there should be information on the occupation and place of residence of both parents, if possible up to three months prior to conception, as well as other socio-eco- nomic data. Such a birth registry is essential for research and prevention efforts.

\section{Competing Interests}

None of the authors have any competing interest, financial or otherwise.

\section{Authors' contributions}

GAH conducted the study and will be the corresponding author. JT supervised the study. AM assisted with the final statistical analyses. All three authors read and approved the final manuscript.

\section{Acknowledgements}

We wish to thank the Department of Paediatrics at Cecilia Makiwane Hospital for the permission to analyse the data with regard to birth defects. We also wish to thank all nurses involved in the interviews and finally all mothers who took their time and effort to come to the clinics to be interviewed. Our thanks also go to the staff of the Department of Statistics at the University of Fort Hare who kindly supported the study.

\section{References}

I. Department of National Health: Pesticidal Poisoning in South Africa. 1980-1994. Epidemiological Comments 1994, 22:I I2-I38.

2. Garcia AM: Occupational exposure to pesticides and congenital malformations: a review of mechanisms, methods, and results. Am J Ind Med 1998, 33:232-240.

3. London L: Agrichemical hazards in the South African farming sector. S Afr Med J 1992, 6:560-564.

4. London L: Agrichemical safety practices on farms in the western Cape. S Afr Med J 1994, 84:273-278.

5. Garcia AM, Fletcher T, Benavides FG and Orts E: Parental exposure to pesticide and congenital malformations. Scand J Work Environ Health 1998, 24:473-480.

6. Shaw GM, Wasserman CR, O'Malley CD, Nelson $V$ and Jackson RJ: Maternal pesticide exposure from multiple sources and selected congenital anomalies. Epidemiology 1999, I:60-66.

7. Kristensen P, Irgens LM, Andersen A, Bye AS and Sundheim L: Birth defects among offspring of Norwegian farmers. I967-1991. Epidemiology 1997, 8:537-544.

8. White FM, Cohen FG, Sherman G and McCurdy R: Chemicals, birth defects and stillbirths in New Brunswick: associations with agricultural activity. CMAJ 1988, I 5: I I7- 124.

9. Savitz DA, Whelan EA and Kleckner RC: Effects of parents occupation exposure on risk of stillbirth, pre-term delivery, and small-for-gestational-age infants. Am J Epidemiology I989, I 29:1201-1218.

10. Bell EM, Hertz-Picciotto I and Beaumont J): A case-control study of pesticide and fetal death due to congenital anomalies. Epidemiology 2001, I2:148-156.

II. Restropo M, Monoz N, Day N, Parra J, Hernandez C, Blettner M and Giraldo A: Birth defects among children born to a population occupationally exposed to pesticides in Colombia. Scand J Work Environ Health 1990, 16:239-246.

12. London $L$ and Myers JE: Critical issues for agrichemical safety in South Africa. Am J Ind Med 1995, 27:1-14.

13. London L: Occupational Epidemiology in Agriculture: A Case Study in the Southern African Context. Int J Occup Environ health 1998, 4:245-256.

14. Restropo M, Monoz N, Day N, Parra J, de Romero L and NguyenDinh $X$ : Prevalence of adverse reproductive outcomes in a population occupationally exposed to pesticide in Colombia. Scand J Work Environ Health 1990, 16:232-238.

15. Arbuckle TE, Savits DA, Mery LS and Curtis KM: Exposure to Phenoxy Herbicides and the Risk of Spontaneous Abortion. Epidemiology 1999, 10:752-760.

16. White FMM, Cohen FG, Sherman G and McCurdy R: Chemicals, birth defects and stillbirths in New Brunswick: association with agricultural activity. Can Med Assoc J 1988, I 38: I I 7-I 24. 
17. Kristensen P: Pesticides and reproduction. Epidemiology 1999, 10:103-105.

18. Blatter BM, Roelveld N, Ziehlhuis GA, Mullaart RA and Gabreels F): Maternal occupational exposure during pregnancy and the risk of spina bifida. Occup Environ Med 1996, 53:80-86.

19. Lindbohm ML: Effects of parental exposure to solvents on pregnancy outcome. J Occup Environ 1995, 37:908-9|4.

20. Garcia AM, Fletcher T, Benavides FG and Orts E: Parental agricultural work and selected congenital malformations. $\mathrm{Am} J$ Epidemiol 1999, 149(1):64-74.

21. Mead M: A Comment on the Role of Women in Agriculture. In: Women and World Development. American Association for the Advancement of Science Edited by: Tinker I and Bramsen B. Overseas development council Library of Congress Card Catalog No 76-16704; 1976:9-1I.

22. Gittens C: No easy pickings. in Farmer's Weekly: 18-19. 18 May 200 ।

\section{Pre-publication history}

The pre-publication history for this paper can be accessed here:

http://www.biomedcentral.com/content/backmatter/ 1476-069x-2-11-b1.pdf

Publish with Bio Med Central and every scientist can read your work free of charge

"BioMed Central will be the most significant development for disseminating the results of biomedical research in our lifetime."

Sir Paul Nurse, Cancer Research UK

Your research papers will be:

- available free of charge to the entire biomedical community

- peer reviewed and published immediately upon acceptance

- cited in PubMed and archived on PubMed Central

- yours - you keep the copyright 